\title{
0 apoio institucional como dispositivo para a implantação do acolhimento nos serviços de saúde
}

\author{
Maria Elizabeth Barros de Barros ${ }^{(a)}$ \\ Mônica Maria Raphael da Roza ${ }^{(b)}$ \\ Carla Ribeiro Guedes ${ }^{(c)}$ \\ Gustavo Nunes de Oliveira ${ }^{(d)}$
}

\section{Introdução}

Desde sua criação em 1988, o Sistema Único de Saúde (SUS) tem experimentado inúmeros avanços e desafios, encontrando-se em permanente curso de mudanças, debatendo formas de organização do sistema, dos serviços e do trabalho, que definem os modos de se produzir saúde.

Muitos dispositivos têm sido criados como forma de enfrentar os impasses cotidianos na rede e nos serviços. Dentre vários deles, podemos citar experiências de implantação do acolhimento como uma forma de qualificar o acesso dos usuários ao sistema de saúde e ofertar maior resolutividade ${ }^{1,2}$.

O acolhimento é uma diretriz da Política Nacional de Humanização do Ministério da Saúde ${ }^{3,4}$ e tem como proposta reverter a lógica de organização e de funcionamento dos serviços, partindo de alguns princípios, como indicados por Franco et al. ${ }^{2}$ :

1 Atender a todas as pessoas que procuram serviços de saúde, garantindo acessibilidade universal e resolutividade. Assim, o serviço assume sua função de acolher, escutar e dar resposta capaz de resolver os problemas de saúde da população.

2 Reorganizar o processo de trabalho, de forma que este desloque seu eixo do médico para uma equipe multiprofissional, a "equipe de acolhimento", que se encarrega da escuta do usuário, comprometendo-se a resolver seu problema de saúde. A consulta médica é requisitada só para os casos em que ela se justifica. Dessa forma, todos os profissionais de nível superior e ainda os auxiliares e os técnicos de enfermagem participam da assistência direta ao usuário.

3 Qualificar a relação trabalhador-usuário, que deve se dar por parâmetros de solidariedade e cidadania.

A implantação de dispositivos na Política Nacional de Humanização ocorre acompanhada de um método que procura superar a racionalidade gerencial hegemônica. Essa racionalidade se atualiza nos serviços de saúde com seus moldes tayloristas, com ênfase no trabalho fragmentado, na gestão verticalizada, pautada na disciplina e no controle como eixo central de gestão ${ }^{5}$.

Tais modelos de gestão se exercem por mecanismos que controlam e assujeitam, que produzem efeitos de docilização e disciplinarização nos corpos,

\footnotetext{
(a) Departamento de Psicologia, Centro de Ciências Humanas e Sociais, Universidade Federal do Espírito Santo. Av. Fernando Ferrari, s/n, Goiabeiras. Vitória,

ES, Brasil. 29055-180.

betebarros@uol.com.br (b) Departamento de Psicologia, Universidade Federal Fluminense - Polo Universitário Rio das Ostras (UFF/PURO). Rio das Ostras, RJ, Brasil. monica.roza@gmail.com (c) Departamento de Saúde e Sociedade, Instituto de Saúde Coletiva, Universidade Federal Fluminense. Niterói, RJ, Brasil. carla. rguedes@gmail.com (d) Departamento de Saúde Coletiva, Faculdade de Ciências da Saúde, Universidade de Brasília. Brasília, DF, Brasil. oliveiragn@gmail.com
} 
e que, em seu efeito na produção de sujeitos, tentam infantilizar, desresponsabilizar e despotencializar os trabalhadores. Modelos que se expressam quando se trata de sua atualização nas instituições de saúde, de modo inseparável, nas estratégias do cuidar. Diante desse quadro que acreditamos que se encontram desafiadas, em especial, as políticas públicas de saúde a traçar estratégias metodológicas que interfiram nesse estado de coisas.

Nesse sentido, o apoio institucional apresenta-se como um dispositivo que tem como objetivo ampliar a capacidade de análise e intervenção dos sujeitos e dos grupos e é uma estratégia para possibilitar a democracia institucional ${ }^{5}$.

Este artigo visa, portanto, articular o apoio institucional à implantação do dispositivo acolhimento nos serviços de saúde por meio de um estudo de caso em uma policlínica no SUS. Com esse objetivo, tomamos como referência teórica-conceitual as formulações de Campos ${ }^{5,6}$ sobre o método Paideia e as produções da análise institucional francesa, a partir de Lourau ${ }^{7}$ e Guattari ${ }^{8}$.

\section{Referenciais teóricos}

\section{O apoio institucional}

O apoio institucional é concebido por Campos ${ }^{5}$, em sua formulação do "apoio Paideia", como uma postura metodológica que perspectiva a reformulação dos tradicionais mecanismos de gestão. Apoio é uma função que reformula o modo tradicional de se fazer coordenação, planejamento, supervisão e avaliação em saúde. É uma função de fomento e acompanhamento de processos de mudança nas organizações, misturando e articulando conceitos e tecnologias advindas da análise institucional para pensar a gestão.

É tarefa primordial do apoio a oferta de suporte ao movimento de mudança deflagrado por coletivos, buscando fortalecê-los no próprio exercício da produção de sujeitos em seus processos de mudança. O objeto de trabalho do apoiador é, sobretudo, o processo de trabalho de coletivos que se organizam para produzir, nesse caso, saúde.

O apoiador se insere em um processo de movimento de coletivos, auxiliando e ofertando conceitos e tecnologias para a análise das instituições, buscando novos modos de operar, funcionar, agir e produzir das organizações, considerando os pressupostos da democracia institucional e de autonomia. Além disso, o apoio parte e considera a inseparabilidade entre a clínica e a política, entre cuidado e a gestão - que se interferem mutuamente - e a transversalidade das práticas e dos saberes nas organizações.

A função apoio se apresenta, nessa medida, como dispositivo para ampliar a capacidade de reflexão e análise de coletivos. Segundo Benevides ${ }^{9}$ (p. 275):

O apoiador não é simplesmente um consultor, que palpita sobre o trabalho e diz das mazelas do grupo; nem tampouco sua ação se resume à assessoria, indicando caminhos a partir de um suposto saber externo que atua sobre o grupo. Sem negar estas especificidades, o apoiador é alguém que penetra no grupo para acioná-lo como dispositivo, se apresentando como um "fora dentro incluído", alguém que atravessa o grupo não para feri-lo, ou para anunciar suas debilidades, mas para operar junto com o grupo em um processo de transformação na própria grupalidade e nos modos de organizar o trabalho e de ofertar ações e estratégias de saúde.

Como poderíamos relacionar a função apoio a um processo de democratização institucional? Como nos indica Benevides, a função apoio, ao operar com o grupo, viabiliza mudança na grupalidade e, assim, transformação no modo como o trabalho está organizado, imprimindo processos cogestivos de funcionamento, instituindo e fortalecendo democracia institucional, na medida em que o apoiador opera com os grupos e não sobre eles. Aqui, então, o método da roda ou Paideia é uma estratégia importante, na medida em que implica na formação de rodas, de espaços coletivos, grupalidades outras, análise de processos de trabalho. Método que produz agenciamentos capazes de integrar 
as dimensões política, pedagógica, analítica e administrativa das organizações, criando condições para a emergência de processos cogestivos ${ }^{10}$, afirmando e ampliando protagonismo distribuído dos trabalhadores, promovendo "democracia institucional", que é um efeito esperado pelo exercício do apoio institucional. A democracia se amplia pelo método Paideia, ou método da roda, de forma a produzir mudanças no processo de trabalho e reposicionamento subjetivo, uma vez que esse processo implica, necessariamente, produção de sujeitos. Produção de saúde e produção de sujeitos não se dissociam. O apoio institucional como dispositivo, portanto, opera mudanças dos próprios trabalhadores, que se instrumentalizam para efetivar transformações nos processos de trabalho. Essa é a aposta.

\section{As contribuições da análise institucional para pensar o apoio institucional}

O dispositivo apoio toma as instituições como sua matéria de trabalho, na forma de um apoio institucional, e se envolve com os desafios no processo de instituição de outros modos de trabalhar em saúde. Com as contribuições da análise institucional francesa, toma-se a instituição em seu sentido ativo; busca-se a análise das condições institucionais para a existência dos grupos; procede-se por análise coletiva das implicações, ou seja, dar visibilidade aos modos como apoiadores institucionais, trabalhadores e gestores se vinculam aos processos de trabalho; promove-se crise nos especialismos, de forma a indagar os modos autoritários como os saberes dos especialistas se impõem e desqualificam os demais saberes da experiência; atenta-se para os processos em curso no estabelecimento e não se foca, apenas, as formas instituídas e consolidadas de funcionamento das organizações; busca-se, assim, a transversalização da análise, questionando o contratualismo verticalizante e o horizontalismo basista que reforça os corporativismos. E ainda, toma como inseparáveis pesquisa e intervenção, teoria e prática; subjetividade e política; clínica e política ${ }^{11}$.

O apoio institucional incorpora da análise institucional a transdisciplinarização dos saberes, a compreensão da demanda como processo sempre produzido e não natural, a compreensão da subjetividade como produção, a perspectiva de que é intervindo que se conhece a realidade.

Os conceitos de instituição variam, como nos indica a abordagem institucionalista francesa, passando por um sentido de estabelecimento/organização, de forma a ficar identificada e reduzida à ordem estabelecida, dimensão concebida por Lourau ${ }^{12}$ como o instituído. Mas a instituição não possui apenas uma face instituída. Ela encontra-se tanto além quanto aquém das formas instituídas que lhe identificamos. É também conjunto de regras construídas, decididas, criadas (não naturais). Sendo construída e criada, passa ser vista como processual, como uma composição de processos que fazem e desfazem as formas institucionais, de modo a incluir no conceito e na análise da instituição os processos instituintes das formas. Instituído e instituinte são duas faces da instituição. Instituído e instituinte são simultâneos e sucessivos. Se há aqui distinção, não oposição, nem dicotomia entre uma face e outra. Trata-se de forças em complementaridade e luta.

Sociedade é intrinsecamente histórica, como instituinte quanto instituída - isto é autoalteração. A sociedade instituída não se opõe à sociedade instituinte, como um produto morto à atividade que lhe deu existência; ela representa a fixidez/estabilidade relativa e transitória das formas-figura instituídas. A auto-alteração perpétua da sociedade é o seu próprio ser, que se manifesta pela posição de formas/figuras relativamente fixas e estáveis e pelo estilhaçamento dessas formas/figuras, que forçosamente será posição-criação de outras formas figuras. ${ }^{13}$ (p. 67)

É nesse contexto conceitual/metodológico que situamos a função apoio institucional, que se faz a partir de uma reversão nos modos habituais de fazer intervenção, uma vez que as ações não partem de metas prefixadas, não se atêm à dimensão instituída das instituições. O primado é do caminhar que, no percurso, traça suas metas ${ }^{14}$. O apoio, aqui, dar-se-ia como prática de construção de um plano coletivo de forças, que indica o processo de produção das formas dadas, ou seja, dos modos como são geridos os serviços; a organização do trabalho refere-se, logo, à gênese dos modos instituídos de funcionamento das unidades. 
Tal plano se articula com plano instituído das figuras já estabilizadas, uma vez que o trabalho de apoio considera, além dos contornos estáveis das formas de ser trabalhador, gestor, usuário e serviço, os processos, os jogos de forças que produzem essas formas, indicando que não se trata de formas naturais e inquestionáveis de existência. Essa operação analítica, ao desnaturalizar modos de existência estabilizados, indica-nos a possibilidade de instituirmos outros sujeitos, outros mundos, outros modos de produzir saúde. Longe de limitar o olhar a uma realidade fixa, que está dada, visa à ampliação de nossa concepção de mundo, incluindo esse plano movente da realidade dos serviços que coexiste com o que está instituído.

Tal reversão apresenta algumas características, segundo as quais a orientação do apoio se efetiva: 1) não se faz de modo prescritivo, a partir exclusivamente de regras já prontas, com objetivos previamente estabelecidos; e 2) é imanente, pois é no exercício das ações que ele se faz: é o primado da experiência. Apoio que se faz, portanto, no mergulho na experiência coletiva em que todos estão implicados.

Essa direção segue a máxima da análise institucional formulada na França por Lourau e Guattari8: transformar para conhecer. As práticas se efetivam na articulação entre o campo de intervenção, ou seja, o espaço-tempo acessível àqueles que fazem a intervenção, e o campo de análise, que se constitui a partir do sistema conceitual que direciona a análise.

Ao se colocar em análise valores, interesses, expectativas, compromissos, desejos, crenças, a função apoio, como trabalho de análise, é processual e perspectiva a quebra de formas instituídas para dar expressão aos processos de institucionalização.

Esse modo de operar traz consequências metodológicas importantes, uma vez que nos indica a necessidade de tomar os serviços na sua dupla face, ou seja, como uma forma dada que, devido à franja de virtualidade que carrega consigo, possui inesgotáveis possibilidades dos serviços se constituírem, está em constante movimento, em vias de diferir. Se ficarmos restritos à dimensão das formas, ou seja, se não considerarmos esses dois planos e sua inevitável relação, não conseguiremos apreender uma marca essencial do real que é seu processo de criação. O desafio é justamente intervir nas formas instituídas de funcionamento dos serviços, porém, sem desconsiderar sua dimensão processual, ou seja, esse plano coletivo das forças moventes, em que a criação de novos modos de trabalhar se desenha.

A questão que se coloca para nós, então, é considerarmos o plano de forças como potência de criação - que está sempre ao lado das formas instituídas -, que o trabalho de apoio se vê diante da tarefa de acessar esse plano coletivo uma vez que objetiva transformações dos processos de trabalho em curso nos serviços. Acessar esse plano implica provocar a ampliação do olhar, tirar os antolhos com os quais nos habituamos a olhar o mundo. Trata-se de atiçar a dimensão movente da realidade e fazer uma aposta radical na possibilidade de transformação do que está dado.

Ao aceder a essa dimensão movente a função apoio pode afetar as condições de gênese das realidades instituídas, cristalizadas e sacralizadas, e assim intervir e fazer derivar, por meio de um processo de diferenciação, novas outras formas de trabalhar ainda não atualizadas. Diríamos, em outras palavras, que se trata de uma aposta na capacidade dos viventes de hesitar, liberando os trabalhadores dos automatismos, fazendo-os diferir, suspender ou variar respostas antevistas pelas prescrições. As ações visam a produzir um padrão de comunicação enviesado que deixa vazar outros processos de invenção no trabalho, de produção de saúde e de sujeitos. Função apoio que se faz a partir de um "não lugar", oferecendo-se como deslocamento dos trabalhadores para o lugar de analistas de sua atividade.

Essa direção de análise implica, reafirmamos, considerar que toda situação de trabalho comporta um potencial, uma virtualidade, não uma identidade, e seus modos de funcionamento não são dados a priori. Trata-se de partir da multiplicidade de vetores que produzem os processos de trabalho, plano de produção das formas ${ }^{15}$. Sujeitos, processos de trabalho, relações de poder são vetores e, portanto, inseparáveis do modo de operar. Assim, produzimos uma torção radical no modo substancializado de tomarmos os trabalhadores e os serviços para focar os modos de produção da realidade e dos sujeitos, dessubstancializando os sujeitos e objetos, então tomados a partir dos modos como se conectam. Sujeitos e objetos colocados em relação de intercessão e de interferência um sobre o outro, não 
podendo ser pensados fora dessa mesma relação ${ }^{16}$. Perseguindo a construção de políticas públicas no âmbito da saúde, o trabalho de apoio institucional, no âmbito da Política Nacional de Humanização, segue essa direção de análise. Propõe articular práticas que se atualizam nos serviços de saúde, propiciando, nas equipes, trocas solidárias, afirmando gestão como criação, renormatizando normas de trabalho pelo coletivo de trabalhadores.

A experiência aqui apresentada partiu das contribuições teórico-metodológicas do apoio institucional no âmbito da Política Nacional de Humanização do Ministério da Saúde num serviço de saúde como parte do plano de ação dessa política nos anos de 2008 e 2009 em uma políclínica do SUS, para a implantação do acolhimento.

\section{Da experiência numa policlínica do SUS}

O trabalho desenvolvido emerge em meio a esse debate conceitual metodológico que nos oferece o institucionalismo francês. Partiu, então, das seguintes etapas: 1) contrato do apoio institucional (com a demanda institucional, a análise do cenário e a oferta do apoio institucional), 2) as oficinas (com a análise dos fluxos da porta de entrada e a construção coletiva de um plano de intervenção de implantação do acolhimento), 3) as reuniões de acompanhamento do processo de implantação do acolhimento (com o monitoramento e a avaliação das ações).

\section{O contrato de apoio}

A parceria entre a Política Nacional de Humanização do Ministério da Saúde (PNH/MS) e a policlínica teve início em agosto de 2008. Período em que a equipe de consultores da PNH/MS foi procurada por um dos gestores dessa unidade, com o pedido de que apoiássemos a reorganização da porta de entrada e o processo de implantação da "diretriz-dispositivo" acolhimento na instituição.

A partir dessa solicitação, foram realizadas reuniões mensais na policlínica com a presença de consultores da PNH/MS e a equipe da gestão: direção geral, chefia clínica, coordenação médica do acolhimento, coordenação de enfermagem, coordenação de assistência social, com a finalidade de pactuar o apoio institucional na unidade.

A policlínica funciona no espaço onde era um antigo PAM do Ministério da Saúde. Até meados da década de 1990, a unidade tinha perfil ambulatorial, ganhando novas características após convênio de cogestão entre o Ministério da Saúde e uma universidade pública. Nesse momento, passou a funcionar como clínica Inamps e clínica do Ambulatório do Hospital Universitário.

Em 2007, a nova gestão da policlínica assumiu a proposta de rever a porta de entrada e construir um processo de acolhimento de acordo com as diretrizes da Política Nacional de Humanização.

Nas reuniões com os gestores, foi realizada uma análise dos desafios enfrentados na unidade. Os principais problemas indicados pelo grupo se referiam à enorme fila que se iniciava de madrugada (e que chegava a trezentas pessoas por dia) para marcação de consulta de primeira vez e retorno, e a ilegalidade nas marcações. Havia dificuldade em identificar na fila quem era "primeira vez" e quem era "retorno". Sentiam a necessidade de adequar o espaço físico, separar a fila, organizar a agenda de marcação, pactuar com a rede, organizar protocolos que pudessem identificar condições prioritárias de atendimento.

Outra questão colocada pelo grupo tinha relação com as diferentes formas de vinculação trabalhista existentes na policlínica, o que acarretava dificuldades de relação entre equipes e trabalhadores, tendo sido localizado o problema especialmente na relação dos médicos, com vínculo federal, com o restante dos trabalhadores do serviço. Como a policlínica vinha de uma configuração de serviço ambulatorial do Inamps, contava com mais de uma centena de profissionais médicos, com vínculo federal, os quais já tinham vínculos antigos, todos em processo de aposentadoria, em um espaço máximo de cinco anos. Ao mesmo tempo havia um número significativo de novos profissionais contratados pela universidade que assumira a gestão do serviço. O plano era a substituição dos primeiros, com vínculo federal, pelos novos, da universidade. Havia uma queixa por parte dos 
"novos" de que os "antigos" não se envolviam com nenhuma de suas propostas e "estavam somente esperando o momento de sua aposentadoria". Ao mesmo tempo havia uma notória ausência dos "antigos" nas primeiras oficinas realizadas.

Em fevereiro de 2009, foi construída a proposta de organização de algumas oficinas para atores estratégicos na implementação do acolhimento na unidade, no sentido de envolvê-los no processo e de corresponsabilizá-los. Os consultores da $\mathrm{PNH}$, responsáveis diretamente pelo apoio institucional à unidade, acompanharam todo o processo e a agenda anual pactuada contou com reuniões e oficinas mensais com o grupo de trabalhadores e gestores diretamente ligados à reorganização da porta de entrada.

\section{As oficinas}

Foram realizadas quatro oficinas que contaram com uma média de vinte trabalhadores de diferentes áreas (enfermagem, serviço social, clínica médica, saúde bucal, nutrição, psicologia) e gestores (direção clínica, direção/coordenadores de áreas), envolvidos no processo de implantação do acolhimento da policlínica. A partir da análise do cenário, o grupo passou a estudar os fluxos de porta de entrada com o objetivo de apropriar-se do que realmente se passava nesse contexto.

O fluxograma descritor ${ }^{17}$ configurou-se num instrumento para análise do processo de trabalho. Ele consiste em uma representação gráfica do processo de trabalho, buscando perceber os caminhos percorridos pelo usuário quando procura assistência à saúde, e permite a detecção de seus problemas.

Nas oficinas trabalhamos com a análise do fluxograma de forma coletiva, envolvendo os trabalhadores e gestores da unidade. Concordamos com Franco ${ }^{17}$ que o processo de construção coletiva, além de apresentar um produto permeado por múltiplos saberes, tem o efeito de formar uma opinião entre os trabalhadores em torno da realidade do serviço, como consequência da organização do processo do trabalho e, principalmente, viabilizar um processo autogestivo. No nosso entendimento, o fluxograma se constituiria como importante dispositivo para o fortalecimento e ampliação de autonomia dos trabalhadores na análise dos processos de trabalho naquele serviço, reafirmando o protagonismo dos profissionais.

Partindo das diretrizes conceituais indicadas, procedeu-se à análise dos fluxos de porta de entrada, que foram identificados, descritos na sua dimensão instituída e analisados, dando passagem à dimensão instituinte desses processos. Na fila do serviço de pronto-atendimento, identificou-se três questões a serem problematizadas: o atendimento de idosos se dava alternado com outros usuários; os médicos não faziam guia de referência; e a fila podia durar o dia todo de espera. Por sua vez, na fila da marcação de consultas, o grupo constatou que não havia garantia de retorno para paciente acompanhado, não se conseguia marcar mais de uma especialidade no mesmo dia, e que a fila era alimentada pelos seguintes processos: retorno em uma mesma especialidade; retorno em outra especialidade - primeira vez -; e agendamento de usuários referenciados (serviço de prontoatendimento, hospital universitário e do Estado).

Em seguida foram produzidas análises com o grupo sobre o que denominamos "o lado de fora das filas" e "o lado de dentro das filas". No primeiro item foi analisada a perspectiva do usuário: como transitavam nas filas, porque chegavam tão cedo para formar a fila (às $23 \mathrm{~h}$ do dia anterior), as razões de não procurarem serviços mais próximos de suas residências e os motivos dos serviços os encaminharem para essa unidade. No segundo item interrogamos sobre os processos de trabalho na policlínica: o porquê da concentração das filas pela manhã, os motivos das consultas serem agendadas todas em um único horário, as possibilidades de agendamento das consultas por telefone, as razões do usuário que vem de outro serviço para entrar na mesma fila daqueles que já são atendidos na unidade; e como se situa a policlínica na rede SUS do município e do Estado.

As respostas dadas pelo grupo de trabalhadores e gestores foram analisadas e demonstraram a organização do processo de trabalho na unidade: falta de informação dos usuários em relação aos trânsitos internos (falta de sinalização, divulgação das informações); acesso à unidade por ordem de chegada; ausência de pactuação de fluxos e critérios de referência e contrarreferência; cultura institucional de favorecimento de horário de trabalho dos médicos; dificuldade de vislumbrar a 
possibilidade de utilização de outra forma de organização do acesso programado que não necessitasse da presença física do usuário; desconsideração da proposta de acompanhamento e do vínculo com o usuário no serviço.

Esses movimentos analíticos sobre os fluxos e os processos de trabalho foram primordiais, à medida que entendemos que o modo de implementar a mudança na porta de entrada da unidade é processual e se dá por processos instituintes. Processos estes protagonizados coletivamente pelos trabalhadores e gestores por meio de uma rede de conversações, como assinala Teixeira1.

Nas duas últimas oficinas, priorizamos a construção coletiva de linhas de ações para a transformação da porta de entrada da unidade, e para a adoção do dispositivo acolhimento. Considerando o contexto institucional e da rede SUS no município em que se localiza, o grupo elegeu dois eixos de intervenção: "a policlínica" e "a rede territorial ligada à policlínica". Na policlínica optou-se pela integração de unidades de produção ${ }^{5}$; reordenação dos fluxos e acolhimento no Serviço de Pronto-Atendimento (SPA) e na marcação de consultas; revitalização e produção do cuidado nos espaços comuns. Por sua vez, na rede territorial ligada à policlínica, priorizou-se a criação de fluxos diretos entre a unidade e outros serviços parceiros; criação de protocolos de acesso e contrarreferência junto à rede básica locorregional.

Como as questões citadas requereriam múltiplas frentes de intervenção, houve a necessidade da priorização das linhas de ação. Sendo assim, o grupo reunido em oficina com apoiadores da PNH pactuou, a partir de critérios como viabilidade, situação institucional, medidas em andamento na porta de entrada da policlínica e governabilidade, por iniciar o planejamento de intervenção e transformação pela linha de ação: "Reordenação dos fluxos e acolhimento no SPA e na marcação de consultas", entendendo que essa ação estava já em andamento na policlínica.

Para implementação dessa linha de ação, o grupo entendeu que o acolhimento envolve as seguintes funções:

1 Orientar usuários que não conseguiram agendar consultas sobre especialidades que não são ofertadas pela policlínica.

2 Receber, escutar, avaliar, atender e orientar usuários em sofrimento agudo (avaliar risco, estabilizar, responder demanda) e crônicos (avaliar risco, responder demanda).

3 Informar funcionamento e ofertas do serviço.

No entanto, o serviço de pronto-atendimento da unidade tinha um funcionamento bastante distinto das diretrizes de acolhimento apontadas pelo grupo. O SPA configurava-se como um lugar no qual havia usuários que iam buscar atendimento clínico e outros que iam buscar encaminhamento para especialidades. Havia necessidade, em maior parte das especialidades, de passar no SPA para abrir prontuário. A tomada de decisão pouco levava em consideração a proposta de acompanhamento e o vínculo com o usuário no serviço. O atendimento de idosos se dava de modo alternado com outros usuários, e por fim, alguns médicos não faziam guia de referência. Além disso, todos os médicos do SPA tinham vínculo federal e eram considerados pelo coletivo como profissionais descomprometidos e não cooperantes, pelo fato já mencionado da proximidade de suas aposentadorias.

Diante desse cenário, os apoiadores da PNH e o coletivo de trabalhadores e gestores estabeleceram algumas ações estratégicas:

1 Iniciar o acolhimento na fila de entrada sob responsabilidade de profissional habilitado (serviço social), e criar protocolo de tomada de decisão.

2 Transformar a fila do SPA para que fosse composta por usuários que procurassem atendimento clínico e fila de marcação para que fosse composta por usuários que buscavam agendar consulta especializada já tendo em mãos o encaminhamento correto.

3 Criar processo para que os usuários que eventualmente estejam visivelmente passando mal na fila inicial fossem direcionados diretamente para avaliação clínica de enfermagem, com suporte do médico do acolhimento.

4 Proceder à inclusão dos médicos do SPA nas rodas de discussão, nos grupos de trabalho de maneira cordial, ativa e persistente.

Foram co-construídos também os modos de fazer para viabilizar essas ações:

a) Criar protocolo de tomada de decisão em cada estação de acolhimento: 
1 abordagem inicial na fila inicial; 2 abordagem no guichê SPA; 3 marcação de consulta; 4 no serviço social; 5 avaliação de enfermagem e médica no acolhimento;

b) Montar as estações de acolhimento: 1 definir equipe; 2 pactuar entre equipes, gestão, usuários; discutir coletivamente com cada estação as funções, responsabilidades e fluxos (mantendo atenção ao conjunto do processo de acolhimento).

c) Estabelecer reunião do grupo periódica, constituindo grupos de trabalho transitórios para executar as ações pactuadas.

Ao fim dos ciclos de oficinas, definiu-se também que os consultores da PNH continuariam a fazer apoio por meio de reuniões para o acompanhamento do processo de implantação do acolhimento na unidade.

\section{As reuniões de acompanhamento do processo de implantação do acolhimento na unidade}

Foram realizadas algumas reuniões entre os consultores da $\mathrm{PNH}$ e o grupo de trabalhadores e gestores da policlínica para o acompanhamento e avaliação do processo de implantação do acolhimento na unidade. Nesses encontros, onde mais uma vez foram utilizadas como estratégia metodológica o método Paideia ${ }^{6}$, avanços e desafios foram sinalizados pelo grupo.

Algumas ações planejadas para a porta de entrada precisaram ser revistas e reajustadas. Assim como nas oficinas, a equipe estruturou conjuntamente algumas estratégias para solucionar os desafios diagnosticados.

Avaliamos que a instituição de grupos de trabalho contribuiu para a consolidação do protagonismo dos trabalhadores, propiciando mudanças sem a necessidade constante de remetê-las às gerências formais do serviço. Esses movimentos acabaram por ampliar a necessidade de espaços de cogestão e a formalização desses espaços entre trabalhadores e gestores.

O apoio institucional revelou um desafio crucial: a gestão compartilhada das práticas em saúde. Conforme desdobramos as implicações do projeto do acolhimento, a inseparabilidade entre os modos de cuidar e de gerir entraram em cena, e o grupo passou a se apoderar das decisões sobre os processos de trabalho na unidade.

Conforme aponta Campos ${ }^{5}$, o apoio depende da instituição de alguma forma de cogestão. A instalação de processos cogeridos de transformação de práticas desafia a racionalidade administrativa imperativa no SUS, porque exige a reformulação de mecanismos de gestão tradicionais.

A partir do apoio institucional, o grupo pôde colocar em análise os modos de gestão daquele coletivo, experimentou trabalhar em espaços cogestivos e produziu mudanças na organização da porta de entrada no direcionamento de propiciar maior acesso e resolutividade aos usuários.

\section{Considerações finais}

O estudo viabilizou uma análise da função apoio institucional na construção do acolhimento. Podemos destacar elementos fundamentais desse método: a análise de demanda institucional, a análise situacional do serviço, o contrato com as ofertas de apoio, o trabalho em equipe multiprofissional, a utilização de rodas ampliadas/inclusivas com o envolvimento de trabalhadores e gestores para o debate e decisão, assim como para o planejamento, o monitoramento e a avaliação das ações.

Por meio do mapeamento desses elementos, foi possível ampliar a análise da função apoio institucional com base nos referenciais teóricos adotados (análise institucional francesa e apoio Paideia). Nessa função podem ser descritos alguns princípios básicos:

1) O apoiador aprende que a realidade não se resume ao que é visível/dizível e muito menos aos fatos em si. O real é sempre envolto de virtuais que podem ou não se atualizar.

2) O trabalho de apoiador implica em aprender a lidar com ritmos, velocidades variáveis - é preciso aprender o tempo oportuno da ação. 
3) A função apoio só pode ser exercida com um posicionamento institucional favorável, o qual é sempre dinâmico, fluido, e deve ser sustentado permanentemente.

4) O exercício da função apoio depende de arranjos organizacionais mais ou menos estáveis que permitam e sustentem o posicionamento de apoiador.

5) O exercício da função apoio implica em um preparo para conviver com paradoxos, suportar a duração dos incômodos, conviver e cartografar as linhas de fuga para produzir/apreender o novo.

Nesse sentido, o apoio institucional apresenta-se como um método estratégico para implantação de novos dispositivos do SUS em serviços de saúde por possibilitar a ampliação da democracia institucional.

\section{Colaboradores}

Os autores trabalharam juntos em todas as etapas de produção do manuscrito.

\section{Referências}

1. Teixeira RR. O acolhimento num serviço de saúde entendido como uma rede de conversações. In: Pinheiro R, Mattos R, organizadores. Construção da integralidade: cotidiano, saberes e práticas em saúde. Rio de Janeiro: UERJ, IMS, Abrasco; 2003. p. 89-111.

2. Franco TB, Bueno WS, Merhy EE. O acolhimento e os processos de trabalho em saúde: o caso de Betim, Minas Gerais, Brasil. Cad Saude Publica. 1999; 15(2):345-53.

3. Ministério da Saúde. Política Nacional de Humanização (PNH). Acolhimento com classificação de risco. Brasília (DF): MS; 2009.

4. Ministério da Saúde. Política Nacional de Humanização (PNH). Acolhimento nas práticas de produção de saúde. Brasília (DF): MS; 2006.

5. Campos GW. Um método para análise e cogestão de coletivos. São Paulo: Hucitec; 2000.

6. Campos GW. Saúde Paideia. São Paulo: Hucitec; 2007.

7. Lourau R. Análise institucional. Petrópolis: Vozes; 1995.

8. Guattari F. Revolução molecular. Rio de Janeiro: Brasiliense; 1981.

9. Benevides RB. Grupo: a afirmação de um simulacro [tese]. São Paulo (SP): Pontifícia Universidade Católica; 1994.

10. Oliveira GN. Devir apoiador: uma cartografia da função apoio [tese]. Campinas (SP): Universidade Estadual de Campinas; 2010.

11. Benevides RB, Passos E. Clínica, política e as modulações do capitalismo. Lugar Comum. 2004; 19(20):159-71.

12. Lourau R. O instituinte contra o instituído. In: Altoé S, organizadores. René Lourau: analista institucional em tempo integral. São Paulo: Hucitec; 2004. p. 47-65.

13. Castoriadis C. A instituição imaginária da sociedade. Rio de Janeiro: Paz e Terra; 2000.

14. Escóssia L, Tedesco S. O coletivo de forças como plano de experiência cartográfica. In: Passos E, Kastrup V, Escóssia L, organizadores. Pistas do método da cartografia. Porto Alegre: Sulina; 2009. p. 92-108. 
15. Barros MEB, Benevides RB. Da dor ao prazer no trabalho. In: Santos-Filho S, Barros MEB, organizadores. Trabalhadores da Saúde: muito prazer! Protagonismo dos trabalhadores na gestão do trabalho em Saúde. Ijuí: Unijuí; 2007. p. 61-72.

16. Barros MEB, Fonseca TMG. Psicologia e processos de trabalho: um outro olhar. Psico (PUCRS). 2004; 22(1):25-37.

17. Franco TB. O fluxograma descritor e projetos terapêuticos para análise de serviços de saúde em apoio ao planejamento: o caso de Luz (MG). In: Merhy EE, Magalhães Júnior HM, Rimoli J, Franco TB, Bueno WS, organizadores. O trabalho em saúde: olhando e experenciando o SUS no cotidiano. São Paulo: Hucitec; 2007. p. 161-98. 
Este artigo apresenta o apoio institucional como dispositivo para a implantação do acolhimento nos serviços de saúde. A função apoiador, como apoio a processos de mudança nas organizações, articula conceitos e tecnologias advindos da análise institucional e da gestão. O apoio institucional vem sendo utilizado como dispositivo metodológico pela Política Nacional de Humanização para a construção e a consolidação do Sistema Único de Saúde (SUS). Nos resultados foram descritas e analisadas as etapas do processo de apoio a um serviço de saúde. O apoio institucional colocou em análise os modos de gestão daquele coletivo, propiciou trabalhos em espaços cogestivos e produziu mudanças na organização da porta de entrada no direcionamento de um maior acesso e resolutividade aos seus usuários. Considera-se que o apoio se apresenta como um dispositivo estratégico para criação de novas estratégias no SUS por possibilitar a ampliação da democracia institucional.

Palavras-chave: Apoio institucional. Acolhimento. Política Nacional de Humanização. Policlínica. Sistema Único de Saúde (SUS).

\section{Institutional support as a device for implementing reception in healthcare services}

This paper presents institutional support as a device for implementing reception in healthcare services. The supporter function provides support for change processes in organizations and links concepts and technologies that come from institutional analysis and management. Institutional support has been used as a methodological device within the Brazilian Humanization Policy to construct and consolidate the Brazilian Health System (SUS). The stages of the support process within a healthcare service were described and analyzed here. Institutional support placed the management methods of that public service under analysis, gave rise to work in comanagement spaces and produced changes in how the entry to that service was organized, towards greater access and problem-solving capacity for service users. It can thus be considered that support is a strategic device for creating new strategies within SUS, through enabling expansion of institutional democracy.

Keywords: Institutional support. Reception. Brazilian Humanization Policy. Polyclinic. Brazilian Health System (SUS).

\section{El apoyo institucional como dispositivo para la implementación de la acogida en los servicios de salud}

En este artículo se presenta el apoyo institucional como dispositivo para la implementación de la acogida en los servicios de salud. La función del apoyador (como apoyo a los procesos de cambio en las organizaciones) articula conceptos y tecnologías provenientes del análisis institucional y de la gestión. El apoyo institucional se ha utilizado como dispositivo metodológico por parte de la Política Brasileña de Humanización para la construcción y la consolidación del Sistema Brasileño de Salud (SUS). En los resultados se describen y analizan las etapas del proceso de apoyo a un servicio de salud. El apoyo institucional analizó los modos de gestión de ese colectivo, propició trabajos en espacios de cogestión y produjo cambios en la organización de la puerta de entrada y en la dirección de un mayor acceso y capacidad de resolución a los usuarios. Se considera que el apoyo se presenta como un dispositivo estratégico para la creación de nuevas estrategias en SUS por posibilitar la ampliación de la democracia institucional.

Palabras clave: Apoyo institucional. Acogida. Política Brasileña de Humanización. Policlínica. Sistema Brasileño de Salud (SUS). 
